\title{
Cystic and alveolar echinococcosis of the hepatobiliary tract - the role of new imaging techniques for improved diagnosis
}

\author{
Christoph F. Dietrich ${ }^{1,2}$, Wiem Douira-Khomsi ${ }^{3}$, Hassen Gharbi ${ }^{4}$, Malay Sharma ${ }^{5}$, Xin Wu \\ Cui $^{6}$, Zeno Sparchez ${ }^{7}$, Joachim Richter ${ }^{8}$, Adnan Kabaalioğlu', Nathan S. S. Atkinson ${ }^{10}$, \\ Dagmar Schreiber-Dietrich ${ }^{11}$, Dong $\mathbf{Y i}^{12}$
}

${ }^{1}$ Department Allgemeine Innere Medizin (DAIM), Kliniken Hirslanden, Beau Site, Salem und Permanence, Bern, Switzerland, ${ }^{2}$ Sino-German Research Center of Ultrasound in Medicine, The First Affiliated Hospital of Zhengzhou University, Zhengzhou, China, ${ }^{3}$ Hopital d'Enfants Bechir Hamza, Tunis, Tunisia, ${ }^{4}$ Department of Radiologie, Ibn Zohr Clinic, Tunis, Tunisia, ${ }^{5}$ Department of Gastroenterology, Jaswant Rai Speciality Hospital, Meerut, India, ${ }^{6}$ Department of Medical Ultrasound, Tongji Hospital, Tongji Medical College, Huazhong University of Science and Technology, Wuhan, China, ${ }^{7} 3^{\text {rd }}$ Medical Department, University of Medicine and Pharmacy "Iuliu Hatieganu", Institute for Gastroenterology and Hepatology “O. Fodor" Cluj-Napoca, Romania, ${ }^{8}$ Institute of Tropical Medicine and International Health, Charité Universitätsmedizin, Berlin, Germany, ${ }^{9}$ Akdeniz University Hospital, Department of Radiology, Antalya, Turkey, ${ }^{10}$ Department of Gastroenterology, Waitemata District Health Board, Auckland, New Zealand, ${ }^{11}$ Pediatric Department, Caritas Krankenhaus Bad Mergentheim, Academic Teaching Hospital of the University of Würzburg, Germany, ${ }^{12}$ Department of Ultrasound, Zhongshan Hospital, Fudan University, Shanghai, China

\begin{abstract}
Cystic echinococcosis (CE) or hydatidosis (hydatid cysts) is an infection with a wide spectrum of manifestations, from asymptomatic infection to fatal disease. Ultrasound (US) allows screening, diagnosis, differential diagnosis, treatment guidance and follow-up of CE under many circumstances. Hydatid cysts are predominantly observed in the liver. Herewith we present a review to demonstrate established and innovative imaging features of CE of the hepatobiliary tract.
\end{abstract}

Keywords: Tropical medicine; parasites; guidelines; contrast enhanced ultrasound; elastography

\section{Introduction}

Cystic echinococcosis (CE) or hydatidosis (hydatid cysts), is an infection caused by the larval stage (metacestode) of the cestode (tapeworm) Echinococcus granulosus. In humans, it may result in a wide spectrum of manifestations, from asymptomatic infection to fatal disease. Correspondingly, the imaging characteristics are broad.

Received 22.11.2019 Accepted 12.01.2020

Med Ultrason

2020, Vol. 22, No 1, 75-84

Corresponding author: Prof. Dr. med. Christoph F. Dietrich Department Allgemeine Innere Medizin (DAIM), Kliniken Hirslanden, Beau Site, Salem und Permanence, Bern, Switzerland E-mail: c.f.dietrich@googlemail.com
Imaging is useful to stage disease in differing organs, including the location and number of cysts, along with more detailed characterization of CE. Local experience influences the choice of preference for ultrasound (US), computed tomography (CT), or magnetic resonance imaging (MRI), though basic portable ultrasound devices have been adequate to screen patients in endemic areas with $E$. granulosus infections [1,2]. The early descriptions have been published by Gharbi et al [3-11]. Recent publications on the epidemiology, anatomical locations, cyst structure, US classification, diagnostic imaging and clinical work up, discuss in detail the advantages of established imaging modalities [12].

The liver (predominantly the right lobe) is the most commonly affected organ by E. granulosus infection in adults and is most often asymptomatic. Symptoms occur 
when the cyst becomes larger than $10 \mathrm{~cm}$ or infiltrates surrounding structures. If this includes portal vein thrombosis, signs of portal hypertension or the Budd-Chiari syndrome may result. Infiltration of bile ducts may cause colicky pain, obstructive jaundice, cholangitis and abscess formation. Infiltration of the diaphragm and pleural cavity may cause peritoneal-pleural (bronchial) fistula, whilst rupture into the peritoneal cavity may lead to a life threatening peritonitis.

Most recently we summarized the current knowledge on hepatic echinococcosis, focusing particularly on defining stages via standard imaging modalities [12]. In brief, the WHO imaging categories include the active parasitosis stages CE1 (unilocular) and CE2 (multilocular with daughter cysts) and the inactive stages CE4 and CE5. These frequently non-viable stages (CE4 and CE5) are echogenic with increasing degrees of fibrosis and calcification. Category CE3 cysts are in the process of degenerating and so defined as "transitional active" and can be further subdivided by morphology; CE3a is morphological characterized by the so-called "water-lily" sign representing floating membranes, whilst subgroup CE3b is characterized predominantly by solid daughter-cyst components. The presence of daughter cysts, whether ruptured or calcified, guides decisions regarding local ablative treatment [13-20]. Unfortunately, morphological signs may not distinguish between vital and avital echinococcosis, which is key to differentiation of stages CE3a and CE3b.

Alveolar echinococcosis (AE) results from infection with Echinococcus multilocularis; taxonomically from the same genus as E granulosus but with different manifestations and disease course. It presents as infiltrative mass lesions almost exclusively within the liver, varying in size from sub-millimeter to $3 \mathrm{~cm}$ [21], but needs to be considered in the differential of atypical cystic lesions.
In this paper we feature images demonstrating the wide variety of imaging features but also include typical findings when newer imaging modalities are utilized - contrast enhanced ultrasound (CEUS), elastography, imaging fusion or positron emission tomography.

\section{Differentiating vital and avital echinococcosis}

The optimal method to differentiate between viable and sterile echinococcosis remains uncertain. CEUS (case of the month, www.efsumb.org) [22-26], positron emission tomography (PET) and MRI [27] may have potential to differentiate. In principle, demonstration of concurrent inflammation suggests viable echinococcosis but it may be also a sign of superinfection of the cyst. Inflammatory reactions in the liver can be displayed by perihepatic lymphadenopathy [28-37], focal changes to vascularity and perfusion in the surrounding liver parenchyma [38-40], or by demonstrating increased metabolic turnover using PET technology. The role of artificial intelligence in the imaging of $\mathrm{CE}$ is promising but has not been evaluated so far $[41,42]$.

\section{Perihepatic lymphadenopathy}

The inflammatory process within organs frequently leads to hyperplasia of draining regional lymph nodes. Lymph node enlargement within the hepatoduodenal ligament may be present in patients with acute [34] or chronic liver and pancreatic diseases including chronic virus hepatitis C [30,36,37,43], autoimmune hepatitis [44], primary biliary cirrhosis [45], primary sclerosing cholangitis [35] and other liver [32] and pancreatic [46] diseases. Lymph node enlargement in the liver hilum may reflect inflammatory activity and/or the immunological response of the host [37]. Lymph nodes in the hepatoduodenal ligament can be non-invasively detected using modern imaging techniques such as US [28,29,31,33,34]. In our personal experience, enlarged perihepatic lymph nodes are a typical sign of viable echinococcosis (fig 1).

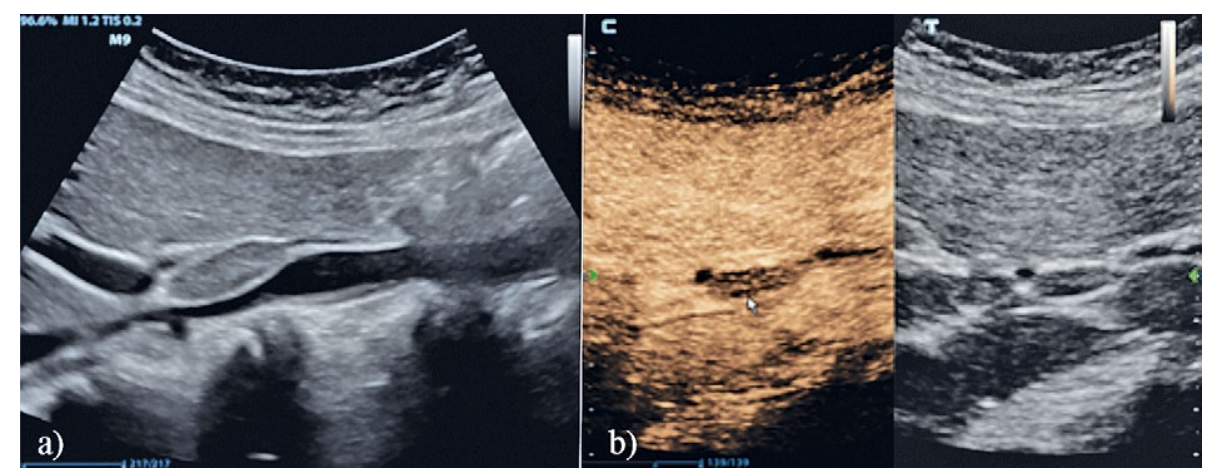

Fig 1. An asymptomatic 51 y/o female, is found to have presumably avital endstage echinococcosis. Signs of concomitant inflammatory reaction, perihepatic lymphadenopathy, are demonstrated by B-mode imaging (a). The use of Contrast enhanced ultrasound (CEUS) demonstrates early wash out from the lymph nodes, consistent with the inflammatory reaction. CEUS is useful to demonstrate the architecture of pathological lymph nodes. Here, normal architecture is displayed, and no circumscript malignant infiltration could be shown. 


\section{Contrast enhanced ultrasound (CEUS)}

Contrast enhanced ultrasound (CEUS) has been available for more than twenty years, with guidelines and recommendations published for its use in liver imaging $[38,39,47]$, non-liver applications [48] and US guided procedures [13,20,49-53]. CEUS in echinococcosis has not been evaluated to date but to our experience it may show a hyperenhancing rim in the surrounding parenchyma as a sign of inflammation. Commentaries elaborating on these recommendations are also published [15,54-57]. In the context of hydatid cysts, there is only scarce data available. CEUS may distinguish hydatid cysts from neoplasms; the absence of contrast enhancement in $\mathrm{CE}$ due to fluid-filled avascular cysts (fig 2) may be demonstrated.

CEUS demonstrates perifocal inflammatory reactions, as nodular zones of peripheral ring enhancement [22] (fig 3) are seen. Thus, echinococcal cysts can differentiated from dysontogenetic cysts under some circumstances [47,58]. Future prospective studies are required to refine the characteristics and utility of CEUS for hydatic disease. In addition to serological tests and grey scale US, CEUS imaging could be integrated as an easily accessible tool helping to describe hypervascularization due to active perilesional inflammation of echinococcal manifestations. CEUS may further help to differentiate between $\mathrm{CE}$ and alveolar echinococcosis (AE) and also to evaluate treatment outcome [59]. Previous study results revealed that CEUS and PET-CT have good interrater reliability in determining the activity of hepatic alveolar echinococcosis [60]. The metabolic activity in alveolar echinococcosis as assessed by FDG-PET has been found to correlate with CEUS vascularity in lesions of the liver, suggesting CEUS may represent a cost-effective tool in resource allocation to FDG-PET examination [61]. CEUS images of large hepatic AE lesions are more complex than that of the small lesions. Large AE lesions can be hypoechoic with mixed content with or without circular rim enhancement or as lesions with no internal area enhancement with circular rim enhancement. The small lesions generally present circular rim enhancement and non-enhancement internal area [62]. CEUS is regarded as an important tool in monitoring hepatic alveolar echinococcosis. Dimensions of the parasitic lesions are displayed more precisely through CEUS than in B-mode. With currently available methods however, CEUS quantification has no benefit in monitoring hepatic alveolar echinococcosis lesions in daily clinical practice [63].

\section{Shear wave elastography (SWE)}

SWE was introduced more than ten years ago to liver imaging [64-67] and non-liver applications [66,68-70].

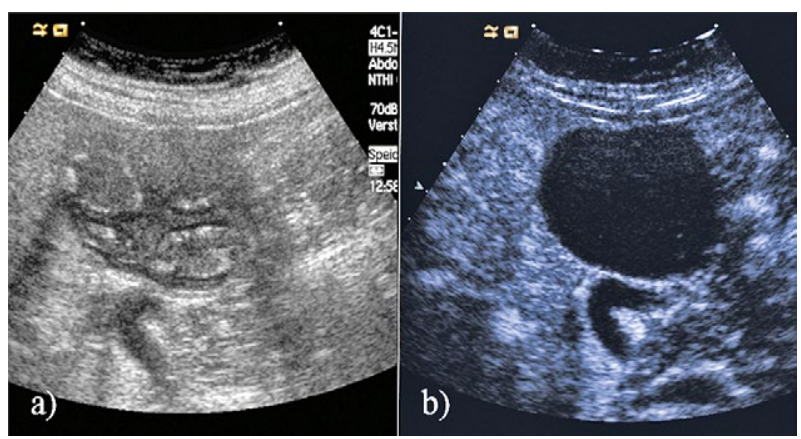

Fig 2. Hydatid cyst displayed by B-mode (a) and CEUS (b). CEUS allows differential diagnosis to solid tumours

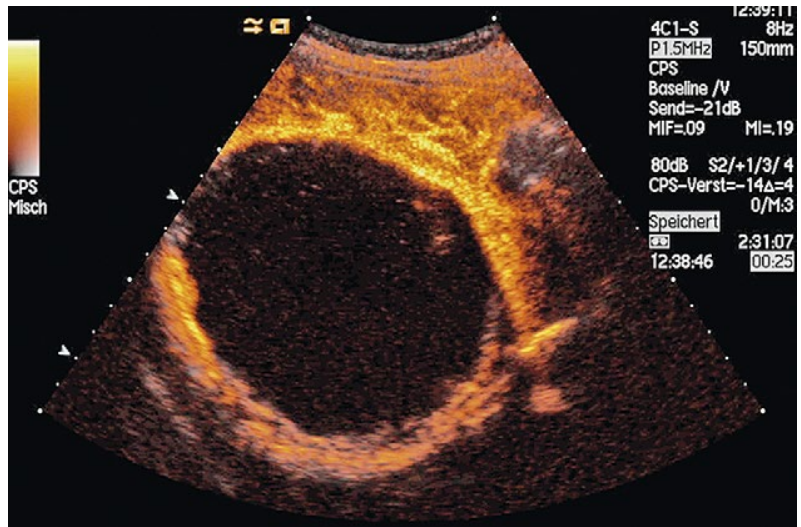

Fig 3. Contrast enhancement of the capsule and surrounding liver parenchyma are seen, consistent with a concomitant inflammatory reaction to the hydatid cyst.

Additional clinically relevant commentaries to supplement the published recommendations are also available $[28,31]$. There are however no published data on the use of SWE in hydatid cysts. Like CEUS, SWE is a new method which needs to be evaluated in CE. Elastography techniques may be helpful to characterize hydatid cysts though do not differentiate stages [71] and may differentiate hepatic neoplasms from 'tumor-like' hydatid cysts. Type I HC has a similar echo pattern to a simple cyst. The elastography value of the cysts is zero in SWE. Type V is pure calcific and very heterogenous. The other types have heterogeneous internal components [71]. Further research is required. The combined approach is shown in figure 4.

\section{Fusion imaging}

Fusion imaging is a technique which combines a new US transducer with a dynamic volume navigation system, integrating a patients' previously acquired MRI DICOM image data into a real time volume navigation. It thus displays synchronized side-by-side MRI and US images in the same plane, allowing a precise position tracking of the US transducer, which facilitates accurate localization 


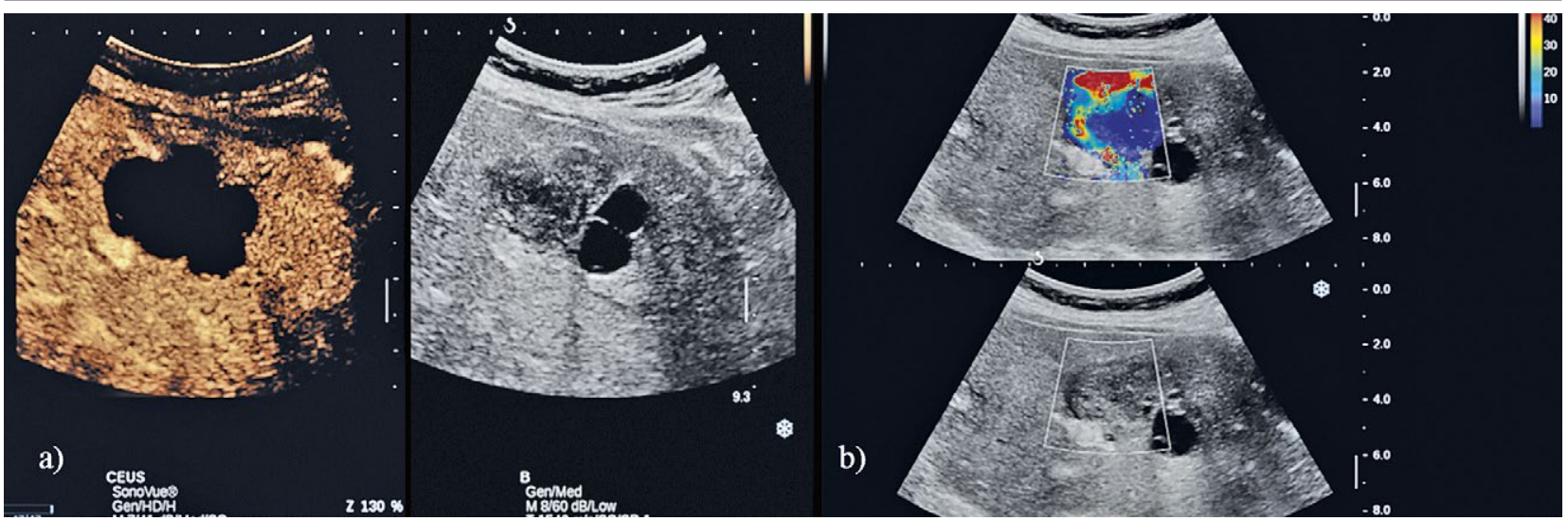

Fig 4. Hydatid cyst displayed by CEUS (a) and SWE (b). Note the additional information with localisation next to a portal vein branch (b) and the stiffness values which may reflect the stage of diseases (b).

of target lesions, with a high degree of confidence during real time US scanning [72-74]. In recent years, fusion imaging methods have been widely used in percutaneous ablation treatment of liver malignancies $[72,75,76]$. During the local ablative or medical treatment of hydatid cysts, fusion images might be helpful to correctly identify focal liver lesions and to realize real time monitoring of treatment (fig 5).

\section{Positron Emission Tomography (PET)}

${ }^{18} \mathrm{~F}-\mathrm{FDG} \mathrm{PET} / \mathrm{CT}$ demonstrates metabolic activity and so can effectively determine the biological boundary of liver AE along with the metabolic activity of surviving liver following autologous liver transplantation [77] and is, therefore, recommended for the initial assessment and follow-up of human AE [78]. In a recent study, CEUS and ${ }^{18}$ F-FDG PET showed good inter-rater reliability in determining the activity of hepatic $\mathrm{AE}$ [60]. Combining FDG-PET/CT with anti-EmII/3-10 antibody levels, better predicts echinococcosis-larval activity after long-term benzididazole therapy for non-resectable alveolar infection, than either parameter alone [79]. Delayed ${ }^{18}$ F-FDG PET facilitates differentiation of active and inactive liver lesions in AE patients [80].

PET/MRI also provides comparable diagnostic information for $\mathrm{AE}$ management. The reduction in radiation exposure compared to PET/CT may be of particular importance for children and young patients not amenable for curative surgery requiring repeated long-term followup with dual imaging modalities [78].

\section{Differential diagnosis}

The clinicians should be aware of the changing epidemiology of hepatic cystic lesions, as echinococcosis has spread to previously non-endemic Western European countries [81]. Accurate diagnosis of CEs is essential because the mortality of these lesions is higher than for simple cysts, estimated between 2-5\% [82]. US is the first

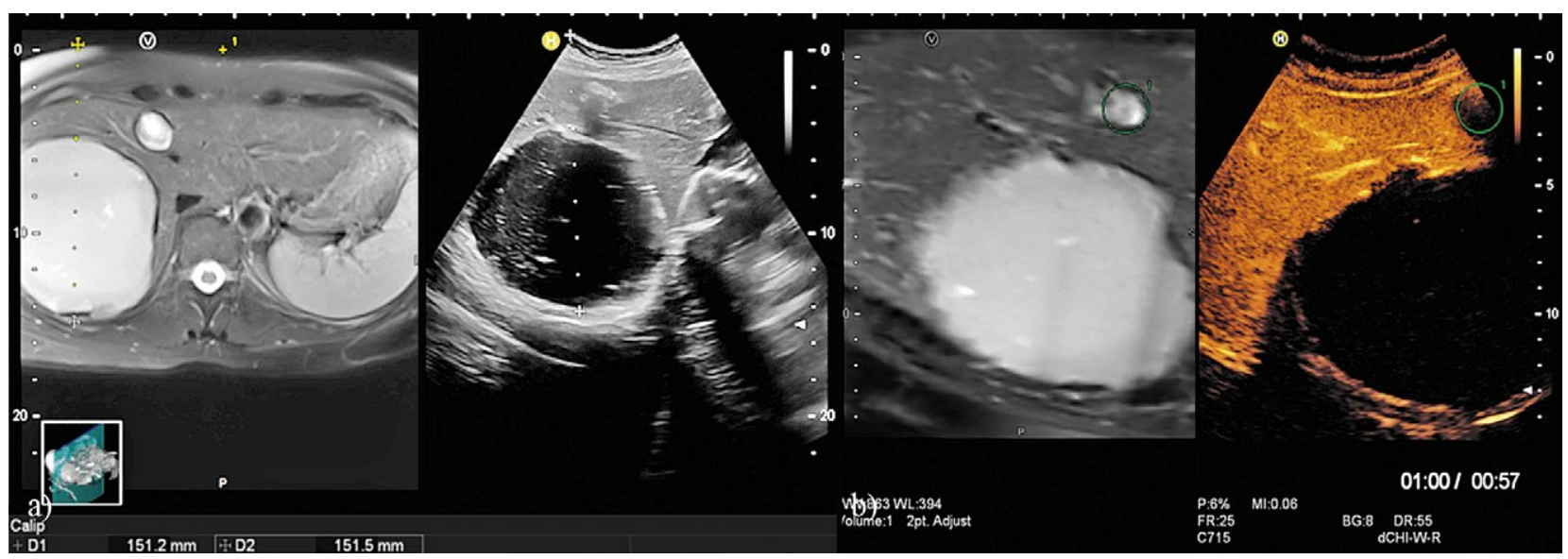

Fig 5. Fusion imaging using RVS with magnetic resonance imaging (a, left), conventional B-mode ultrasound (a, right) and magnetic resonance imaging ( $a$, left) with contrast enhanced ultrasound ( $b$, right). The images can be overlayed to correctly identify focal lesions and to monitor before and after local ablative or medical treatment. 
Table I. Ultrasound features for the diagnosis of monocytic diseases of the liver (after [87], adapted)

\begin{tabular}{llll}
\hline & Cystic echinococcosis & Alveolar echinococcosis & Cystadenoma and cystadenocarcinoma \\
\hline Border & Laminated & Irregular & Irregular \\
Shape & Round or oval & Irregular & Round or oval \\
Echo pattern & Anechoic or atypical & $\begin{array}{l}\text { Hyperechogenic outer ring } \\
\text { and hypoechogenic centre }\end{array}$ & Hypoechogenic with hyperechogenic septations \\
Appearance & Multiseptated & Multivesicular & $\begin{array}{l}\text { Septated and/or solid structures } \\
\text { (papillary projections) }\end{array}$ \\
Wall & & Wall enhancement \\
Posterior acoustic shadow & & Present (calcified areas) & Present (calcified areas) \\
\hline
\end{tabular}

choices of imaging in the diagnosis of $\mathrm{CE}$, with a specificity near $90 \%$ [83]. Typical US features are observed in $70 \%$ of echinococcosis and include an irregular shape and border, hyperechogenic outer ring, hypoechogenic center, multi-vesicular appearance and acoustic shadowing due to calcified areas. Atypical US features include small hyper-echogenic nodules (amorphous AE), large lesions with massive necrosis (pseudocyst) which might be confused with neuroendocrine tumour metastases [84] or sarcoma $[85,86]$, small calcified lesions (inert AE) [87] and liver cystadenoma or cystadenocarcinoma [88].

The US features useful for differentiating between $\mathrm{CE}, \mathrm{AE}$ and cystadenoma and cystadenocarcinoma are summarized in table I [89].

\section{Haemorrhagic hepatic cysts}

Echinococcosis should also be differentiated from haemorrhagic hepatic cysts, which is aided by serial imaging. Features of the later include decreasing cyst size, progressive centrifugal enhancing pattern on dynamic contrast-enhanced CT or MRI, a hypointense rim with central hyperintensity on T2-weighted MRI, and cyst wall calcification [90].

\section{Complications of hydatid cysts in the liver}

Growing hydatid cysts may be asymptomatic or may cause secondary effects through local compression, erosion into local structures or rupture e.g., into the peritoneal space (fig 6). Direct rupture of a hydatid cyst occurs when both the pericyst and endocyst break, allowing free spillage of hydatid material into the surrounding anatomical channels, adjacent organs, or free body cavities [91]. There are several types of direct rupture, including into the gastrointestinal tract, peritoneal cavity, diaphragm, pleural space, bronchi (with development of cystobronchial fistula), pericardium, and skin [91,92].

\section{Rupture into biliary tree (communicating rupture)}

Compression and displacement of the biliary ducts are frequent. At the point of contact with a biliary duct, a rupture may occur. Communication of a CE with the biliary tree occurs in up to $90 \%$ of cases. This high frequency is due to incorporation of the small biliary ducts into the pericyst during cyst growth [92]. A communicating intra-biliary rupture may be occult, usually through small fissures (seen in 10-37\% of patients), or frank (3$17 \%$ ) $[93,94]$. Occult rupture is usually silent but may be accompanied with signs of suppuration or evolve into frank rupture. In a frank rupture, daughter vesicles and fragmented membranes escape into the biliary tree causing obstruction, cholangitis or septicemia [94]. Acute pancreatitis and acute cholecystitis caused by hydatid material have been described [94-97].

There are several US criteria to diagnose intrabiliary rupture of a hydatid cyst [91,94,98-100] (fig 6).

- The ruptured cyst is often multivesicular, has a polycyclic shape, septa or irregular echogenic areas in its interior.

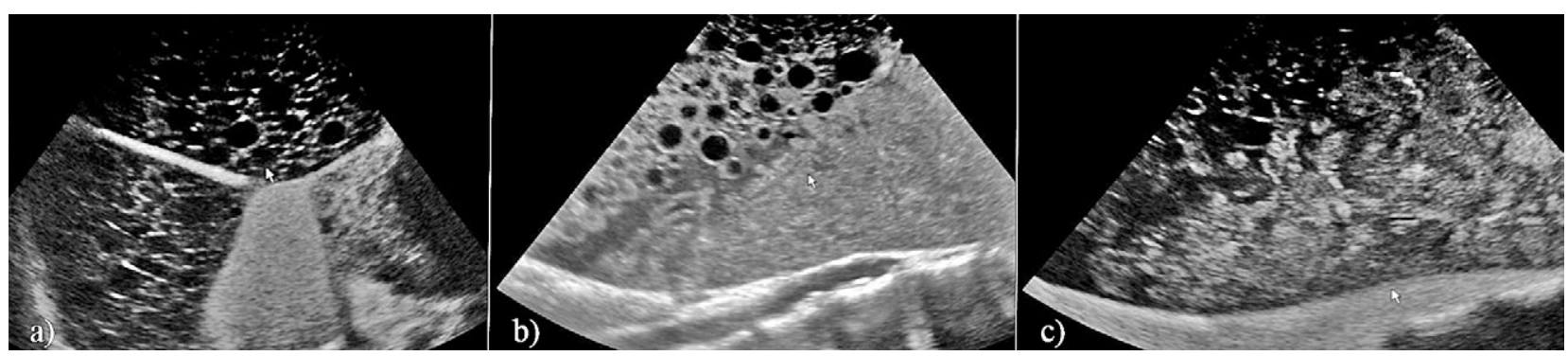

Fig 6. Hydatid cyst of the liver, ruptured. CEUS allows differential diagnosis of enhancing (solid tumour) and non-enhancing (e.g., parasitosis) pathology. The images show the contrast enhancing liver to the right (a,b) and the enhancing aorta distally (c). In all images non-enhancing hydatid vesicular material is shown in the peritoneal space. 
- A loss of continuity of the cyst wall adjacent to the bile duct representing the site of communication is a pathognomonic direct sign of cyst perforation in the biliary tree but is very rarely seen

- Dilatation of the biliary tree occurs with biliary obstruction

- The presence of small cystic images in the biliary ducts may represent daughter cysts, and is a very specific sign of rupture but poorly sensitive. Linear hyperechoic images and non-shadowing material may be found in biliary ducts and are the expression of hydatid membranes and hydatid sand respectively.

- Thickened, double layered bile ducts wall are expression of cholangitis.

In a series of 15 cases, the sensitivity of US to diagnose intra-biliary rupture of a hydatid cyst was $66.7 \%$ [93]. Early evacuation of the cyst together with its germinative membrane and the involved biliary tract is important. Whilst avoiding spillage into the peritoneal cavity, treatment of the remaining cavity according to its location, size, and the presence of infection may be considered (fig 7). Decreasing the pressure in the biliary tract may be achieved by T-tube drainage [101].

\section{Peritoneal hydatid cysts (peritoneal seeding)}

Peritoneal hydatid cysts (peritoneal seeding) are generally secondary to hepatic involvement and most common after previous surgery for hydatid cyst complication. They can also appear after a peritoneal cyst rupture. The prevalence of abdominal involvement with hydatid disease is approximately $10-13 \%[91,92]$. The diagnosis can be made easily with US, because of the characteristic appearance of daughter cysts anywhere in the peritoneal cavity.

\section{Involvement of the diaphragm and thoracic cavity}

Involvement of the diaphragm and thoracic cavity occurs in $0.6 \%-16 \%$ of cases of hepatic hydatid disease localized in the posterior segment of the right hepatic lobe.

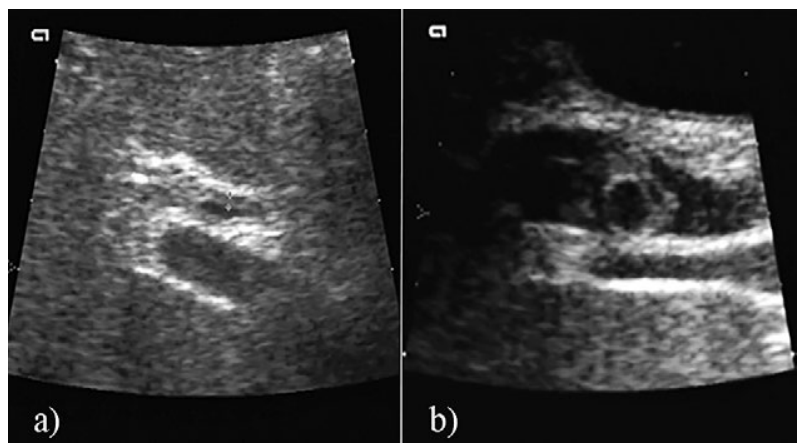

Fig 7. Rupture of a hepatic hydatid cyst into the biliary tree. Linear echogenic material in the CBD on US is indicative of hydatid membranes. Ultrasound 2 days after endoscopic removal of hydatid membranes: common biliary duct of normal size with thick, double layered walls (a). Intrabiliary masses with cystic areas inside, representing daughter vesicles (b).

Trans-diaphragmatic migration usually occurs at the level of bare area of the liver, with simple adherence to the diaphragm, then rupture into the pleural cavity, seeding into the pulmonary parenchyma, or chronic bronchial fistula $[91,92]$. US examination reveals the hepatic CE, pleural effusion, or basal consolidation of the liver [102, 103]. A diaphragmatic defect or fistula is rarely seen by US. Intracavity application of US contrast agents in the instance of CE drainage may depict the hepatic-bronchial fistula (Z.S., personal observation).

\section{Secondary infection of the hydatic cyst}

Bacterial superinfection of a hydatid cyst occurs only after communication or direct rupture of a cyst with subsequent passage of bacteria. This occurs in 5\%-8\% of all $\mathrm{HC}$ cases and up to $25 \%$ of ruptured cysts $[91,92,104]$. The US features are similar to other hepatic abscesses: poor delimitation, mixed internal echoes, and air-air, air-fluid or fluid-fluid levels within the cyst $[91,92,105]$. However, as these US signs are the expression of a direct or communicating rupture, they do not necessarily imply

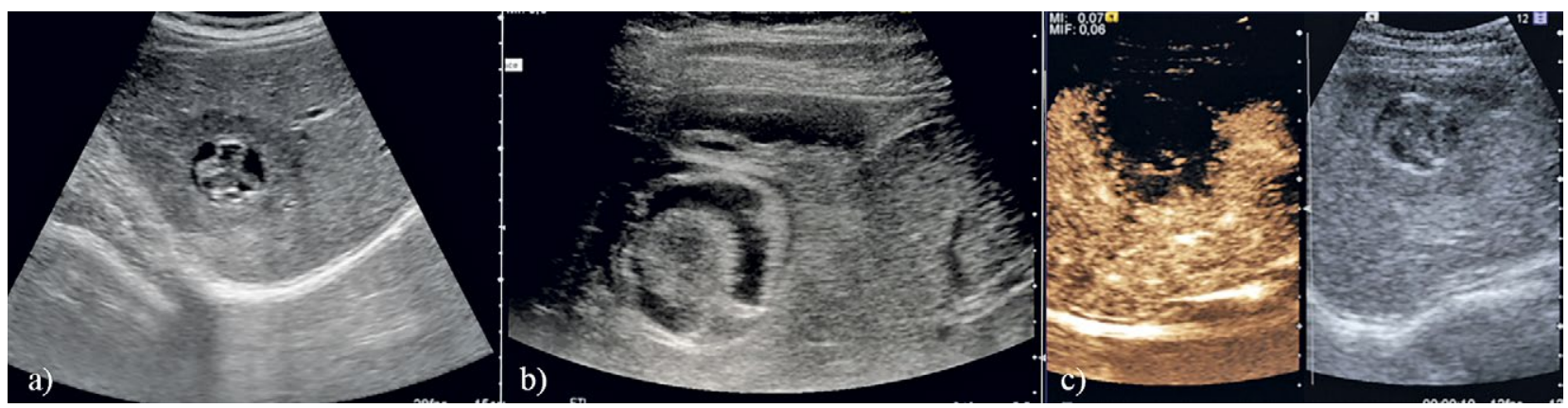

Fig 8. Infected hepatic hydatid cyst. US demonstrates a $3 \mathrm{~cm}$ cyst with detached membrane, echogenic internal echoes. The surrounding liver parenchyma is hypoechoic (a). A small volume of ascites near the liver surface was seen (b). CEUS arterial phase images reveal two zones around the cystic lesion: a non-enhancing circular area consistent with pericystic abscesses $(>)$ and a hypervascular outer area representing peri-abscess inflammation $(\rightarrow)(\mathrm{c})$. 
infection [91,104]. A hypervascular area around the lesion represents inflammatory liver parenchyma changes secondary to infection [92], which can be identified by contrast enhanced CT and CEUS (fig 8).

\section{Compression of hepatic vessels}

Compression of hepatic vessels (portal branches or hepatic veins) is rarely seen. Imaging may reveal portal vein thrombosis with or without cavernous transformation (in lesions located mostly in the caudate lobe or near the hepatic bifurcation) or Budd-Chiari like changes (veno-venous collaterals) [92].

In conclusion, new imaging methods add important information for better understanding of the various manifestations of echinococcosis. Future studies should be performed to confirm the promoted additional value.

Acknowledgement: The authors thank the Bad Mergentheimer Leberzentrum e.V. for support.

\section{Conflict of interest: none}

\section{References}

1. Dietrich CF, Goudie A, Chiorean L, et al. Point of Care Ultrasound: A WFUMB Position Paper. Ultrasound Med Biol 2017;43:49-58

2. Barbieri M, Severi MA, Pirez MI, Battistoni J, Nieto A. Use of specific antibody and circulating antigen serum levels in the hydatid immunodiagnosis of asymptomatic population. Int J Parasitol 1994;24:937-942.

3. Gargouri M, Ben Amor N, Ben Chehida F, et al. Percutaneous treatment of hydatid cysts (Echinococcus granulosus). Cardiovasc Intervent Radiol 1990;13:169-173.

4. Gharbi HA, Cheikh MB, Hamaza R, et al. Rare sites of hydatid disease in children. Ann Radiol (Paris) 1977;20:151157.

5. Mechmeche R, Ben Cheikh M, Bousnina A, Gharbi HA, Ben Ismail M. Hydatid cyst of the heart in children. A series of nine cases. Ann Radiol (Paris) 1984;27:173-181.

6. Gharbi HA, Hassine W, Brauner MW, Dupuch K. U1trasound examination of the hydatic liver. Radiology 1981;139:459-463.

7. Hassine W, Dupuch K, Gharbi HA. Value of ultrasonography in hydatid liver disease in children : a report on 42 cases (author's transl). J Radiol 1980;61:323-327.

8. Abdeselem K, Hassine W, Gharbi HA. Biliary complications of hepatic hydatid cysts. Echographic diagnosis. Med Chir Dig 1982;11:189-191.

9. Horchani A, Hassine W, Gharbi HA, Saied H, Ayed M, Zmerli S. Contribution of echotomography in the diagnosis of hydatid cysts of the kidney. Apropos of 43 confirmed cases. J Urol (Paris) 1983;89:515-520.

10. Kefi M, Sayed S, Hentati M, et al. Anesthesia and resuscitation in the surgery of hydatid cysts. Tunis Med 1985;63:559-562.
11. Ben Amor N, Gargouri M, Gharbi HA, et al. Treatment of hepatic hydatid cyst in sheep by echographic puncture. Tunis Med 1986;64:325-331.

12. Brunetti E, Tamarozzi F, Macpherson C, et al. Ultrasound and Cystic Echinococcosis. Ultrasound Int Open 2018;4:E70-E78.

13. Dietrich CF, Lorentzen T, Appelbaum L, et al. EFSUMB Guidelines on Interventional Ultrasound (INVUS), Part III - Abdominal Treatment Procedures (Short Version). Ultraschall Med 2016;37:27-45.

14. Lorentzen T, Nolsoe CP, Ewertsen C, et al. EFSUMB Guidelines on Interventional Ultrasound (INVUS), Part I. General Aspects (Short Version). Ultraschall Med 2015;36:464-472.

15. Dietrich CF, Chiorean L, Potthoff A, Ignee A, Cui X, Sparchez Z. Percutaneous sclerotherapy of liver and renal cysts, comments on the EFSUMB guidelines. Z Gastroenterol 2016;54:155-166.

16. Dietrich CF, Cui XW, Chiorean L, Appelbaum L, Leen E, Ignee A. Local ablative procedures of the liver. $\mathrm{Z}$ Gastroenterol 2015;53:579-590.

17. Dietrich CF, Nuernberg D. (Eds.). Interventional Ultrasound: A Practical Guide and Atlas. 1st Edition. Stuttgart, New York, Delhi, Rio: Thieme; 2014.

18. Brunetti E, Kern P, Vuitton DA; Writing Panel for the W-I. Expert consensus for the diagnosis and treatment of cystic and alveolar echinococcosis in humans. Acta tropica 2010;114):1-16.

19. Brunetti E, Garcia HH, Junghanss T; International CE Workshop in Lima Peru, 2009. Cystic echinococcosis: chronic, complex, and still neglected. PLoS Negl Trop Dis 2011;5:e1146.

20. Lorentzen T, Nolsoe CP, Ewertsen C, et al. EFSUMB Guidelines on Interventional Ultrasound (INVUS), Part I. General Aspects (long Version). Ultraschall Med 2015;36:E1-E14.

21. Kantarci M, Bayraktutan U, Karabulut N, et al. Alveolar echinococcosis: spectrum of findings at cross-sectional imaging. Radiographics 2012;32:2053-2070.

22. Dietrich CF, Mueller G, Beyer-Enke S. Cysts in the cyst pattern. Z Gastroenterol 2009;47:1203-1207.

23. Dietrich CF. Endobronchialer Ultraschall-EBUS (Update 2017). Ultraschall Med 2018;39:564-565.

24. Barreiros AP, Dong Y, Ignee A, Wastl D, Dietrich CF. EchoScopy in scanning abdominal diseases; a prospective single center study. Med Ultrason 2019;21:8-15.

25. Nielsen MB, Cantisani V, Sidhu PS, et al. The Use of Handheld Ultrasound Devices - An EFSUMB Position Paper. Ultraschall Med 2019;40:30-39.

26. Dietrich CF, Tana C, Caraiani C, Dong Y. Contrast enhanced ultrasound (CEUS) imaging of solid benign focal liver lesions. Expert Rev Gastroenterol Hepatol 2018;12:479-489.

27. Hosch W, Junghanss T, Stojkovic M, et al. Metabolic viability assessment of cystic echinococcosis using high-field 1H MRS of cyst contents. NMR Biomed 2008;21:734-754.

28. Chiorean L, Cui XW, Klein SA, et al. Clinical value of imaging for lymph nodes evaluation with particular emphasis on ultrasonography. Z Gastroenterol 2016;54:774-790. 
29. Chiorean L, Barr RG, Braden B, et al. Transcutaneous Ultrasound: Elastographic Lymph Node Evaluation. Current Clinical Applications and Literature Review. Ultrasound Med Biol 2016;42:16-30.

30. Schreiber-Dietrich D, Pohl M, Cui XW, Braden B, Dietrich $\mathrm{CF}$, Chiorean L. Perihepatic lymphadenopathy in children with chronic viral hepatitis. J Ultrason 2015;15:137-150.

31. Cui XW, Hocke M, Jenssen C, et al. Conventional ultrasound for lymph node evaluation, update 2013. Z Gastroenterol 2014;52:212-221

32. Barreiros AP, Chiorean L, Braden B, Dietrich CF. U1trasound in rare diffuse liver disease. Z Gastroenterol 2014;52:1247-1256.

33. Cui XW, Jenssen C, Saftoiu A, Ignee A, Dietrich CF. New ultrasound techniques for lymph node evaluation. World J Gastroenterol 2013;19:4850-4860.

34. Braden B, Faust D, Ignee A, Schreiber D, Hirche T, Dietrich CF. Clinical relevance of perihepatic lymphadenopathy in acute and chronic liver disease. J Clin Gastroenterol 2008;42:931-936.

35. Hirche TO, Russler J, Braden B, et al. Sonographic detection of perihepatic lymphadenopathy is an indicator for primary sclerosing cholangitis in patients with inflammatory bowel disease. Int J Colorectal Dis 2004;19:586594.

36. Dietrich CF, Stryjek-Kaminska D, Teuber G, Lee JH, Caspary WF, Zeuzem S. Perihepatic lymph nodes as a marker of antiviral response in patients with chronic hepatitis $\mathrm{C}$ infection. AJR Am J Roentgenol 2000;174:699-704.

37. Dietrich CF, Lee JH, Herrmann G, et al. Enlargement of perihepatic lymph nodes in relation to liver histology and viremia in patients with chronic hepatitis C. Hepatology 1997;26:467-472.

38. Claudon M, Dietrich CF, Choi BI, et al. Guidelines and good clinical practice recommendations for Contrast Enhanced Ultrasound (CEUS) in the liver - update 2012: A WFUMB-EFSUMB initiative in cooperation with representatives of AFSUMB, AIUM, ASUM, FLAUS and ICUS. Ultrasound Med Biol 2013;39:187-210.

39. Claudon M, Dietrich CF, Choi BI, et al. Guidelines and good clinical practice recommendations for contrast enhanced ultrasound (CEUS) in the liver--update 2012: a WFUMBEFSUMB initiative in cooperation with representatives of AFSUMB, AIUM, ASUM, FLAUS and ICUS. Ultraschall Med 2013;34:11-29.

40. Dietrich CF, Sharma M, Gibson RN, Schreiber-Dietrich D, Jenssen C. Fortuitously discovered liver lesions. World J Gastroenterol 2013;19:3173-3188.

41. Zhou LQ, Wang JY, Yu SY, et al. Artificial intelligence in medical imaging of the liver. World $\mathrm{J}$ Gastroenterol 2019;25:672-682.

42. Wu GG, Zhou LQ, Xu JW, et al. Artificial intelligence in breast ultrasound. World J Radiol 2019;11:19-26.

43. Dietrich CF, Viel K, Braden B, Caspary WF, Zeuzem S. Mediastinal lymphadenopathy: an extrahepatic manifestation of chronic hepatitis C?. Z Gastroenterol 2000;38:143152.
44. Dong Y, Potthoff A, Klinger C, Barreiros AP, Pietrawski D, Dietrich CF. Ultrasound findings in autoimmune hepatitis. World J Gastroenterol 2018;24:1583-1590.

45. Dietrich CF, Wehrmann T, Zeuzem S, Braden B, Caspary WF, Lembcke B. Analysis of hepatic echo patterns in chronic hepatitis C. Ultraschall Med 1999;20:9-14.

46. Dong Y, D'Onofrio M, Hocke M, et al. Autoimmune pancreatitis: Imaging features. Endosc Ultrasound 2018;7:196203.

47. Claudon M, Cosgrove D, Albrecht T, et al. Guidelines and good clinical practice recommendations for contrast enhanced ultrasound (CEUS) - update 2008. Ultraschall Med 2008;29:28-44.

48. Piscaglia F, Nolsoe C, Dietrich CF, et al. The EFSUMB Guidelines and Recommendations on the Clinical Practice of Contrast Enhanced Ultrasound (CEUS): update 2011 on non-hepatic applications. Ultraschall Med 2012;33:3359.

49. Lorentzen T, Nolsoe CP, Ewertsen C, et al. EFSUMB Guidelines on Interventional Ultrasound (INVUS), Part I. General Aspects (Short Version). Ultraschall Med 2015;36:464-472.

50. Sidhu PS, Brabrand K, Cantisani V, et al. EFSUMB Guidelines on Interventional Ultrasound (INVUS), Part II. Diagnostic Ultrasound-Guided Interventional Procedures (Long Version). Ultraschall Med 2015;36:E15-E35.

51. Jenssen C, Hocke M, Fusaroli P, et al. EFSUMB Guidelines on Interventional Ultrasound (INVUS), Part IV - EUSguided Interventions: General aspects and EUS-guided sampling (Long Version). Ultraschall Med 2016;37:E33E76.

52. Fusaroli P, Jenssen C, Hocke M, et al. EFSUMB Guidelines on Interventional Ultrasound (INVUS), Part V - EUS-Guided Therapeutic Interventions (short version). Ultraschall Med 2016;37:412-420.

53. Jenssen C, Brkljacic B, Hocke M, et al. EFSUMB Guidelines on Interventional Ultrasound (INVUS), Part VI - Ultrasound-Guided Vascular Interventions. Ultraschall Med 2016;37:473-476.

54. Mohaupt MG, Arampatzis S, Atkinson N, et al. Comments and extensions to EFSUMB guidelines on renal interventional ultrasound (INVUS). Med Ultrason 2016;18:351361.

55. Dietrich CF, Horn R, Morf S, et al. Ultrasound-guided central vascular interventions, comments on the European Federation of Societies for Ultrasound in Medicine and Biology guidelines on interventional ultrasound. J Thorac Dis 2016;8:E851-E68.

56. Dietrich CF, Schreiber-Dietrich D, Hocke M. Comments on the EFSUMB non-liver Guidelines 2011. Praxis (Bern 1994) 2012;101:1175-1181.

57. Dietrich CF, Cui XW, Barreiros AP, Hocke M, Ignee A. EFSUMB guidelines 2011: comment on emergent indications and visions. Ultraschall Med 2012;33 Suppl 1:S39-S47.

58. Dietrich CF, Schreiber-Dietrich D, Schuessler G, Ignee A. Contrast enhanced ultrasound of the liver--state of the art. Dtsch Med Wochenschr 2007;132:1225-1231. 
59. Schwarze V, Mueller-Peltzer K, Negrao de Figueiredo G, Lindner F, Rubenthaler J, Clevert DA. The use of contrastenhanced ultrasound (CEUS) for the diagnostic evaluation of hepatic echinococcosis. Clin Hemorheol Microcirc 2018;70:449-455.

60. Li J, Dong J, Yang L, Li X, Song T. Comparison of [(18) F]Fluorodeoxyglucose Positron Emission Tomography and Contrast-Enhanced Ultrasound for Evaluation of Hepatic Alveolar Echinococcosis Activity. Ultrasound Med Biol 2018;44:2199-2208.

61. Ehrhardt AR, Reuter S, Buck AK, et al. Assessment of disease activity in alveolar echinococcosis: a comparison of contrast enhanced ultrasound, three-phase helical CT and [(18)F] fluorodeoxyglucose positron emission tomography. Abdom Imaging 2007;32:730-736.

62. Zhang H, Liu ZH, Zhu H, Han Y, Liu J, Deng LQ. Analysis of contrast-enhanced ultrasound (CEUS) and pathological images of hepatic alveolar echinococcosis (HAE) lesions. Eur Rev Med Pharmacol Sci 2016;20:1954-1960.

63. Kaltenbach TE, Graeter T, Mason RA, et al. Determination of vitality of liver lesions by alveolar echinococcosis. Comparison of parametric contrast enhanced ultrasound (SonoVue(R)) with quantified 18F-FDG-PET-CT. Nuklearmedizin 2015;54:43-49.

64. Bamber J, Cosgrove D, Dietrich CF, et al. EFSUMB guidelines and recommendations on the clinical use of ultrasound elastography. Part 1: Basic principles and technology. U1traschall Med 2013;34:169-184.

65. Cosgrove D, Piscaglia F, Bamber J, et al. EFSUMB guidelines and recommendations on the clinical use of ultrasound elastography. Part 2: Clinical applications. Ultraschall Med 2013;34:238-253.

66. Shiina T, Nightingale KR, Palmeri ML, et al. WFUMB guidelines and recommendations for clinical use of ultrasound elastography: Part 1: basic principles and terminology. Ultrasound Med Biol 2015;41:1126-1147.

67. Ferraioli G, Filice C, Castera L, et al. WFUMB guidelines and recommendations for clinical use of ultrasound elastography: Part 3: liver. Ultrasound Med Biol 2015;41:11611179.

68. Cosgrove D, Barr R, Bojunga J, et al. WFUMB Guidelines and Recommendations on the Clinical Use of Ultrasound Elastography: Part 4. Thyroid. Ultrasound Med Biol 2017;43:4-26.

69. Barr RG, Cosgrove D, Brock M, et al. WFUMB Guidelines and Recommendations on the Clinical Use of Ultrasound Elastography: Part 5. Prostate. Ultrasound Med Biol 2017;43:27-48.

70. Trimboli P, Dietrich CF, David E, et al. Ultrasound and ultrasound-related techniques in endocrine diseases. Minerva Endocrinol 2018;43:333-3340.

71. Duymus M, Menzilcioglu MS, Gok M, Erdem A, Avcu S, Kiris A. The Avaibility of Strain Elastography in a Hydatid Cyst - Interobserver Study. Pol J Radiol 2016;81:310-316.

72. Dong Y, Wang WP, Mao F, Ji ZB, Huang BJ. Application of imaging fusion combining contrast-enhanced ultrasound and magnetic resonance imaging in detection of hepatic cellular carcinomas undetectable by conventional ultrasound. J Gastroenterol Hepatol 2016;31:822-828.

73. Jung EM, Clevert DA. Contrast-enhanced ultrasound (CEUS) and image fusion for procedures of liver interventions. Radiologe 2018;58:538-544.

74. Ignee A, Dong Y, Schuessler G, Baum U, Dietrich CF. Endorectal fusion imaging: A description of a new technique. Endosc Ultrasound 2017;6:241-244.

75. Xu EJ, Lv SM, Li K, et al. Immediate evaluation and guidance of liver cancer thermal ablation by three-dimensional ultrasound/contrast-enhanced ultrasound fusion imaging. Int J Hyperthermia 2018;34:870-876.

76. Kang HJ, Kim JH, Lee SM, Yang HK, Ahn SJ, Han JK. Additional value of contrast-enhanced ultrasonography for fusion-guided, percutaneous biopsies of focal liver lesions: prospective feasibility study. Abdom Radiol 2018;43:32793287.

77. Qin Y, Li X, Zhang Q, et al. Analysis of the clinical value of 18F-FDG PET/CT in hepatic alveolar echinococcosis before and after autologous liver transplantation. Exp Ther Med 2016;11:43-48.

78. Lotsch F, Waneck F, Groger M, et al. FDG-PET/MRI imaging for the management of alveolar echinococcosis: initial clinical experience at a reference centre in Austria. Trop Med Int Health 2019;24:663-670.

79. Ammann RW, Stumpe KD, Grimm F, et al. Outcome after Discontinuing Long-Term Benzimidazole Treatment in 11 Patients with Non-resectable Alveolar Echinococcosis with Negative FDG-PET/CT and Anti-EmII/3-10 Serology. PLoS Negl Trop Dis 2015;9:e0003964.

80. Caoduro C, Porot C, Vuitton DA, et al. The role of delayed 18 F-FDG PET imaging in the follow-up of patients with alveolar echinococcosis. J Nucl Med 2013;54:358-363.

81. Romig T, Dinkel A, Mackenstedt U. The present situation of echinococcosis in Europe. Parasitol Int 2006;55 Suppl:S187-S191.

82. Marrero JA, Ahn J, Rajender Reddy K; Americal College of Gastroenterology. ACG clinical guideline: the diagnosis and management of focal liver lesions. Am J Gastroenterol 2014;109:1328-1347.

83. Rawla P, Sunkara T, Muralidharan P, Raj JP. An updated review of cystic hepatic lesions. Clin Exp Hepatol 2019;5:2229.

84. Mork H, Ignee A, Schuessler G, Ott M, Dietrich CF. Analysis of neuroendocrine tumour metastases in the liver using contrast enhanced ultrasonography. Scand J Gastroenterol 2007;42:652-662.

85. Trojan J, Hammerstingl R, Engels K, Schneider AR, Zeuzem S, Dietrich CF. Contrast-enhanced ultrasound in the diagnosis of malignant mesenchymal liver tumors. J Clin Ultrasound 2010;38:227-231.

86. Dong Y, Wang WP, Cantisani V, et al. Contrast-enhanced ultrasound of histologically proven hepatic epithelioid hemangioendothelioma. World J Gastroenterol 2016;22:47414749 .

87. Bresson-Hadni S, Delabrousse E, Blagosklonov O, et al. Imaging aspects and non-surgical interventional treatment 
in human alveolar echinococcosis. Parasitol Int 2006;55 Suppl:S267-S272.

88. Dong Y, Wang WP, Mao F, et al. Contrast enhanced ultrasound features of hepatic cystadenoma and hepatic cystadenocarcinoma. Scand J Gastroenterol 2017;52:365-372.

89. Lantinga MA, Gevers TJ, Drenth JP. Evaluation of hepatic cystic lesions. World J Gastroenterol 2013;19:3543-3554.

90. Kohno S, Arizono S, Isoda H, Yoshizawa A, Togashi K. Imaging findings of hemorrhagic hepatic cysts with enhancing mural nodules. Abdom Radiol 2019;44:1205-1212.

91. Turgut AT, Akhan O, Bhatt S, Dogra VS. Sonographic spectrum of hydatid disease. Ultrasound Q 2008;24:17-29.

92. Pedrosa I, Saiz A, Arrazola J, Ferreiros J, Pedrosa CS. Hydatid disease: radiologic and pathologic features and complications. Radiographics 2000;20:795-817.

93. Atli M, Kama NA, Yuksek YN, et al. Intrabiliary rupture of a hepatic hydatid cyst: associated clinical factors and proper management. Arch Surg 2001;136:1249-1255.

94. Lewall DB, McCorkell SJ. Rupture of echinococcal cysts: diagnosis, classification, and clinical implications. AJR Am J Roentgenol 1986;146:391-394.

95. Aydin A, Ersoz G, Tekesin O, Mentes A. Hydatid acute pancreatitis: a rare complication of hydatid liver disease. Report of two cases. Eur J Gastroenterol Hepatol 1997;9:211214.

96. Ozcaglayan O, Halefoglu AM, Ozcaglayan T, Sumbul HA. Ultrasonographic diagnosis of acute pancreatitis caused by ruptured hydatid disease to the biliary system. JBR-BTR 2014;97:33-35.
97. Ivanis N, Rubinic M, Gudovic A, Zeidler F. Ultrasound image of an echinococcus daughter cyst in the gallbladder. Ultraschall Med 1994;15:269-271.

98. Mircea PA, Chira R, Pop S, Valean S, Cucu A. Ultrasonography of liver hydatic cyst- various sides of the same disease. Rom J Ultrason 2000;2:155-168.

99. Sparchez Z, Osian G, Onica A, Barbanta C, Tantau M, Pascu O. Ruptured hydatid cyst of the liver with biliary obstruction: presentation of a case and review of the literature. Rom J Gastroenterol 2004; 13:245-250.

100. Marti-Bonmati L, Menor Serrano F. Complications of hepatic hydatid cysts: ultrasound, computed tomography, and magnetic resonance diagnosis. Gastrointest Radiol 1990;15:119-125.

101. Ulualp KM, Aydemir I, Senturk H, et al. Management of intrabiliary rupture of hydatid cyst of the liver. World J Surg 1995;19:720-724.

102. Gogia N, Sharma R, Gamangatti S, Seenu V, Madhusudhan KS, Parshad R. Hepatic hydatid cysts with biliary, and peritoneal rupture and transdiaphragmatic migration. Trop Gastroenterol 2006;27:93-96.

103. von Sinner WN. Ultrasound, CT and MRI of ruptured and disseminated hydatid cysts. Eur J Radiol 1990;11:31-37.

104. Turgut AT, Altin L, Topcu S, et al. Unusual imaging characteristics of complicated hydatid disease. Eur J Radiol 2007;63:84-93.

105. Caremani M, Lapini L, Tacconi D, Giorni P, Corradini S, Giaccherini R. Sonographic management of complicated cystic echinococcosis. J Ultrasound 2007;10:179-185. 